\title{
ETHICAL DILEMMAS IN VALUE DELIVERY: THEORETICAL CONDITIONS
}

\author{
Frode Drevland ${ }^{1}$, Jardar Lohne ${ }^{2}$, and Ole Jonny Klakegg ${ }^{3}$
}

\begin{abstract}
Delivering value for the customer is one of the core tenets of lean construction. However, anyone who is affected by a project is considered a customer of the project. Often, different customers of a project will be at odds with each with regards to what constitutes value for them. This could potentially lead to ethical dilemmas for the project delivery team. This is a subject that has so far been given little attention in literature.

In this paper we set forth a theoretical framework for investigating ethical dilemmas in value delivery that will form the basis for future empirical research on ethical issues related to value delivery. More precisely we examine fundamental reasons for ethical dilemmas occurring in the context of value delivery. We theorize that ethical dilemmas in construction projects typically arises when there is misalignment of value between project stakeholders.
\end{abstract}

Keywords: Lean construction, ethics, value, value delivery.

\section{INTRODUCTION}

One of the core prescripts of the lean philosophy is that we should focus on delivering value to our customers. On the surface this seems a relatively simple and straightforward concept. However, in reality it is actually infinitely complex. For one, value as a concept is ill-defined and ambiguous (Salvatierra-Garrido et al. 2012; Thyssen et al. 2010). This is, however, not the biggest challenge related to delivering customer value.

Although there exist no commonly agreed upon definition of value, it is generally agreed that value is subjective or particular (Drevland and Lohne 2015; Holbrook 1998; Salvatierra-Garrido and Pasquire 2011b), i.e. value is in the eye of the beholder. Herein lies the other challenge in delivering value for our customers. Not only is the term value fuzzy in-and-of-itself, within lean, the term customer refers not only to the paying client, but rather everyone downstream in the production chain and anybody who is affected by the built asset.

Given that value is particular and that we trying to serve widely different customer at the same time, we will inevitable find ourselves in the situation that the different customers have needs and desires that are at odds with each other. How do we prioritize one customer over another?

In the literature search leading up to this paper we found different who authors have offered different views on whose value we should be concerned with in construction projects. E.g. Bertelsen and Emmitt (2005) argues that we need to consider the client as a

1 Assistant Professor, Department of Civil and Environmental Engineering, NTNU - Norwegian University of Science and Technology, Trondheim, Norway, frode.drevland@ntnu.no

2 Research Scientist, Department of Civil and Environmental Engineering, NTNU - Norwegian University of Science and Technology, Trondheim, Norway, jardar.lohne@ntnu.no

3 Professor, Department of Civil and Transport Environmental, NTNU - Norwegian University of Science and Technology, Trondheim, Norway, ole.jonny.klakegg@ntnu.nomailto:jardar.lohne@ntnu.no 
complex system, taking into the account the needs of all the different stakeholder in the client organization, Drevland and Svalestuen (2013) argue that only the value for the paying client is of consequence, while Salvatierra-Garrido et al. (2011a) argue that we must also consider the value for the wider society.

Although the literature does cover different views, we have not found any that contrasts these different views to one another, furthermore, none of the literature that we have seen contains any discussions of the ethical implications. E.g. is it ethical to prioritize the needs of the larger society above the needs of the paying client or vice versa?

In this paper we seek to start to shed a light on this, so far, neglected area of value. The purpose of this paper is to define ethical dilemmas in value delivery from a theoretical point of view. This is a preliminary work that will followed up by empirical studies at a later date to determine how people in the industry experience and handle ethical dilemmas of value delivery.

\section{THEORETICAL FRAMEWORK}

\subsection{Ethical versus lawful}

In the literature on ethical decision making in business, lawful and ethical decisions are often conflated. In his seminal work on ethical decision making by individuals in organizations, Jones (1991) define an ethical decision as "a decision that is both legal and morally acceptable to the larger community". This is a definition that is somewhat at odds with the general ethics literature, where moral and ethical are generally considered synonymous terms. Though often concurrent with, ethics must be separated from the field of the law in order to be fully understood. What is perceived as unethical can - in certain circumstances - be lawful, whilst what is perceived as ethically laudable can be deemed unlawful. E.g. in the legend of Robin Hood, his stealing from the rich (unlawful) in order to give to the poor (ethically laudable) forms, is in fact, a clear example of this distinction.

\subsection{Normative and descriptive ethics}

We can separate ethics into normative and descriptive ethics. The first of these profess judgments concerning the manner of acting in the world. This is ethics as most have encountered it, the lessons propagated being from different traditions such as deontology (Kant 1828), consequentialism (Mill 2002 (1861) etc.), virtue ethics (typically in the tradition from (Aristotle 2009 ( 350-322 BC)) or various contemporary approaches (Focault 1976 etc. Habermas 1992; Lévinas 2014; Sartre 1976). In fact, analyses of this sort seem - more or less consciously - to reveal how little that has been done of ethical analysis within the project management literature.

Descriptive ethics, on the other hand, typically analyses the judgments of behaviour in the world according to the vocabulary of ethics. Rather than developing a framework for judging the appropriateness of actions, such analyses typically investigate the reasons underlying such judgements in specific contexts.

While it is possible to investigate and discuss the ethics of value delivery using a normative approach, we would argue that in the context of construction projects and the construction industry this would result in pure theoretical exercise with little practical benefit. It is more interesting to see what industry practitioners themselves consider ethical and unethical and which issues they face.

Depending on which analytic level an analysis is situated, it is possible to distinguish individually oriented and social ethics (Ray et al. 1999). The first of these concerns the 
individual as moral actor, whilst the latter concerns the ethical qualities of social systems. The intention of this paper is not to carry out any sort of blame game on a personal level. What occupy us here are rather judgments of practitioners as representatives of a group, that is, as professionals within the AEC industry, analysing it as a social system. In Hood'ian terms, the question is not whether or not Robin judges his actions in a certain matter - neither, in fact, the manner by which the sheriff of Nottingham judges them but rather how the social milieus these actors operate within judge them. It is more interesting to examine the differences between the perceptions of the simpletons who judge Robin and those of the elite that support the sheriff, than simply calling into attention the judgements of two single individuals.

\subsection{Virtue-oriented descriptive ethics}

One further distinction needs being made concerning the object of the analysis. As commented by Harris (2008), much of current practice within engineering ethics has 1) revolved around creating ethical codes for preventing unethical conduct by engineers, or 2) around the concern for preventing threats from technology to the health and safety of the public. Harris labels these approaches "preventive ethics", having for salient factor a (negative) rule-based understanding of how to act as an engineer in the world. A consequence of this could be that the descriptive ethical analysis outlined focused on perceptions of such (negative) rule-based understandings of ethics.

As Emison (2006) points out, however, an "[u]navoidable complexity" is what faces engineers in their working life, creating "especially dynamic and unstable ethical conditions". The logical consequence of such an insight is that, as Harris points out, not everything that is important in professional ethics can be expressed by rules in general. Rules cannot, Harris argues, adequately account for the place of discretion, judgment and background knowledge involved in professional judgement. Further, there is an internal and often idealistic component to professional practice that cannot adequately be accounted for by rules.

Within the field of ethics, virtue ethics is typically identified as the preponderant alternative to rule-based understandings of ethics. Virtue ethics differs from most other approaches by being more concerned with the character of the moral actor - that is, why the moral actor is doing what he/she is doing - than in outlining rules for conduct.

From a virtue-oriented descriptive ethics perspective, then, what is of interest to the analysis of professional actors is not the observation of their devotion to rules and regulations, but rather an analysis of their motivations for action when facing the complexity characteristic of their professional life. Questions concerning phenomena such as value delivery form archetypal examples of the challenges involved.

\subsection{Definition of value}

In the lean construction community there is a clear tendency to equate value with benefit, however, the most common definition of value is that is the relationship of what you Give and what you Get, or Costs and Benefits to use another terminology (Drevland and Lohne 2015). This is often shown expressed mathematically as Value=Benefit/Cost, however, it can also be expressed as Value=Benefit-Cost. Although mathematical expressions of value have been criticized (Rooke et al. 2010; Thyssen et al. 2010), we believe they can be beneficial if one is aware of their shortcomings. Specifically that value is not summative (Drevland and Lohne 2015). I.e. it is not possible to evaluate different costs and benefits separately and then sum them up, they have to be considered in one comprehensive value judgement. 
One of the reasons such a definition of value is useful, is that it opens up for the notion of negative value, i.e. the situation where someone gives more than they get. This concept is important when considering all the customers of a project. Some of these could possibly only be negatively affected, i.e. there is no Get or Benefit component for them.

A shift in value for some customer will typically occur from some decision being made. To be able to describe what happens in such as situation, we believe it beneficial to introduce the concepts of baseline value and marginal value. The former being the value of someone for the null or default alternative and the latter how much the value will be shifted if a decision is made.

$V_{X, 0}$ - Baseline value for some entity $\mathrm{X}$ given that the zero or default alternative is chosen.

$\Delta V_{X}$-Marginal shift in value for some entity $\mathrm{Z}$ after a decision is made.

Another couple of ancillary terms that we believe are needed when discussing values are true and perceived value. Value being particular entails that it cannot be objectively measured. This entails that value in reality dependent on perception. However, as given by Drevland and Lohne (2015), the concept of true value can be a beneficial theoretical concept. Perceived value being what someone perceives the value of something to be given the knowledge that they possess, whereas true value is what someone would perceive if they had perfect knowledge.

In addition to knowledge, someone's perception of value will depend upon their values (Drevland and Lohne 2015). Value (singular) and values (plural) are two distinct theoretical concepts. Schwartz and Bilsky (1987) defines values as "(a) concepts or beliefs (b) about desirable states or outcomes (c) that transcend specific situations, (d) guide selection or evaluation of behaviour and events and (e) are ordered by relative importance." With regards to ethical dilemmas values are also important since they will influence what someone will consider an ethical dilemma and how to handle it.

\subsection{Alignment of Value}

Alignment of interest is term that is commonly used in the lean literature to describe how well the interests of different actors line up. However, the actors in question are typically limited to be those that have a formal role in the project, i.e. owner, designers and constructors (see e.g. Mesa et al. 2016). Therefore, we believe that this term is not completely suitable in the context of customer value. Furthermore alignment of interest is also tied to action (Colvin and Boswell 2007). I.e. how is the interest of differs actors to act. Value on the on the other does not necessarily have any connection to action. While it is true that some actors will take an active role in the project to maximise their value, this is not true for all stakeholder, or customers in the lean sense of the word, of the project. Some are just passive recipient of a positive or negative value of the project. We therefore choose to introduce the term value alignment and misalignment.

Value alignment - The situation where increasing the value for A will cause an increase in the Value for B and conversely decreasing the value for A will decrease the value for $\mathrm{B}$.

Value misalignment - The situation where Increasing the value for A will cause a decrease in the Value for B and conversely decreasing the value for A will increase the value for $\mathrm{B}$. 
Table 1 Mathematical expressions for alignment and misalignment.

\begin{tabular}{|c|c|}
\hline Value alignment & $\begin{aligned} V_{A, 0}+\Delta V_{A}>V_{A, 0} & \rightarrow V_{B, 0}+\Delta V_{B}>V_{B, 0} \\
V_{A, 0}+\Delta V_{A}<V_{A, 0} & \rightarrow V_{B, 0}+\Delta V_{B}<V_{B,}\end{aligned}$ \\
\hline Value misalignment & $\begin{aligned} V_{A, 0}+\Delta V_{A}>V_{A, 0} & \rightarrow V_{B, 0}+\Delta V_{B}<V_{B, 0} \\
V_{A, 0}+\Delta V_{A}<V_{A, 0} & \rightarrow V_{B, 0}+\Delta V_{B}>V_{B,}\end{aligned}$ \\
\hline \multicolumn{2}{|c|}{$\begin{array}{l}\text { The degree of value alignment can be varying. We therefore introduce the } t \\
2 \text { to describe the degree of alignment or misalignment. }\end{array}$} \\
\hline \multicolumn{2}{|c|}{$\begin{array}{l}\text { Table } 2 \text { Actor B's degree of value alignment with A when changing the } \\
\text { actor A }\end{array}$} \\
\hline & $\Delta V_{B} \approx 0$ \\
\hline & $\left|\Delta V_{A}\right| \gg\left|\Delta V_{B}\right|$ \\
\hline & $\left|\Delta V_{A}\right| \approx\left|\Delta V_{B}\right|$ \\
\hline & $\left|\Delta V_{A}\right| \ll\left|\Delta V_{B}\right|$ \\
\hline
\end{tabular}

\section{ETHICAL DILEMMAS IN THE CONTEXT OF VALUE DELIVERY}

According to Perry (Perry 2014) an ethical or moral dilemma is a situation where "at least two mutually exclusive actions have a clear moral rational for them or there simply is no moral answer at al." Based on the theoretical framework that we have set forth, we hypothesize that ethical dilemmas, in construction projects, will arise for the project delivery organization and the people working in it whenever a non-negligible misalignment of value happens. In the following we will present different scenarios and some possible misalignments of value that could arise. Note that these are not based on formal research, but rather on the authors experience with the industry and impressions that we have gotten from practitioners over the years. We have included them to help the reader get a concrete grasp of the abstract framework that we have presented.

We have here chosen to focus on external customers of construction projects. While it is clear that there in todays practice also are ethical issues regarding value delivery to internal customers in project (see e.g. Lohne et.al, 2016, for issues arising in the design phase), we believe the move towards relational contracting forms like IPD and Alliancing will alleviate this issue. I.e. aligned of commercial goals entails alignment of value and thereby eliminating internal ethical conflicts.

\subsection{The good of the few versus the good of the many}

In many cases a project will have a negative impact for its immediate neighbours, yet be of great value for society at large. One example is critical infrastructure such as powerlines. Another issue of current interest is related to city densification that is happening in large cities around the world. In some cases, areas that have previously been purely composed 
of single homes only a couple of floors high are no seeing development of high-rise apartment buildings. This significantly the value for existing inhabitants in the area.

Although these issues will normally be politically decided on a municipal level, and not be something that the project delivery organization should be encumbered with, it could still weigh heavily on individuals in the organization if they see this as placing and undue burdens those directly affected by the project.

\subsection{The good of the client versus the good of wider society}

Another, more pertinent variant of the above, could be the good of the client versus the good of wider society. If the contract between the client and wider society, i.e. laws, regulations etc., does not ensure value alignment, ethical dilemmas could arise for the project delivery team. E.g., a client wanting a massive building that negatively affects a city environment, for example, by blocking sightlines or having a blocking effect on pedestrian traffic. The municipality might allow this to be built du to ignorance, i.e. not perceiving what the true effects on the city will be. On the other hand, the architect, being both knowledgeable on the issues from education as well as having been instilled the professional values of their profession, could likely perceive the true situation and experience it as problematic. I.e. should they be true to what their client wants or true to what is the best for the city and the values of their profession?

\subsection{The good of the developer versus the good of the buyer}

The former examples touch upon issues that might occur due to issues of value perception. An even clearer examples of the challenges of perception of value can be found in the context of housing development. In a housing project, increasing value for the developer will be a matter of reducing the cost of the project while maximizing the price each unit can be sold for. In many cases the cost of the project can be reduced without seemingly affecting the value for the customers buying the units, i.e. the perceived value stays the same. However, this could be due to the customers not being sufficiently knowledgeable to correctly asses the true value. E.g. a cost reduction for the developer could lead to a long increase in the maintenance cost that has to be borne by the buyer. In this case there is an alignment of perceived value, but a misalignment of true value.

The buyer, lacking sufficient domain knowledge to properly asses this, will perceive the value to be the same and therefore be willing to pay the same price. An architect or engineer on the other hand will have this knowledge and will able to accurately assess the buyers will be short changed on their value.

\section{DisCUSSION AND CONCLUSION}

The previous scenarios describe situations where value misalignment can occur, and where we believe ethical dilemmas can arise for the project delivery team. However, as we have argued in the theoretical framework, we believe that a descriptive approach has to be taken in analysing ethical issues in construction projects. Therefore, while we hypothesize that such situations will give birth to ethical dilemmas, we cannot state for at fact that these scenarios will always lead to ethical dilemmas. It is not given that industry professionals will experience ethical issues if they find themselves in such situations. E.g. if someone's values dictate that the paying client always comes first, then they might not experience any ethical dilemmas, even in the case where there is a strong misalignment of value between the paying client and the other customers of the project. 
Furthermore, it is not only interesting to understand what is considered ethical and unethical in the context of value delivery. If the goal is to address the issues in practical terms, we also need to know how often they occur and how people typically act when faced with these kinds of ethical dilemmas. When faced between a value misalignment between the client and other customer, an architect or engineer might, for example, choose to be blindly loyal to the client, or decide to go behind the clients back and optimize value for the different customers based on their own conception of what is the fairest situation overall.

If are to develop tools and methods for optimizing value delivery in projects we need to have a notion of how people are prone to act in this sense. E.g. a process that only considers the value for the paying client might be seen as inherently unethical by members of the project delivery team, and its use could be sabotaged. If so, it would probably be beneficial to bring in the value for other customers. This would make the process more transparent and less likely that team members will make value adjustments or rebalancing of their own accord. People will typically go along with decisions that they don't agree with a long as they have been able to voice their concerns (Lencioni 2002).

Much of this pure speculation, and we need more knowledge about practitioners' actual views on these issues. In this paper, we have presented a theoretical framework for analysing ethical dilemmas in construction projects. This lays the groundwork for a later empirical study of the phenomenon. Our aim for future research is to answer:

1. What value misalignments are experienced in practice and how frequently?

2. Do designers and constructors experience ethical dilemmas due to these misalignments?

3. How are these situations handled by designers and constructors?

\section{REFERENCES}

Aristotle. (2009). The Nicomachean Ethics. ARISTOTLE (2009). The Nicomachean Ethics. , Oxford, Oxford World's Classics, Oxford.

Bertelsen, S., and Emmitt, S. (2005). "The client as a complex system." 13th Ann. Conf. of the Int'l. Group for Lean Construction, 73-79.

Colvin, A. J. S., and Boswell, W. R. (2007). "The problem of action and interest alignment: Beyond job requirements and incentive compensation." Human Resource Management Review, 17(1), 38-51.

Drevland, F., and Lohne, J. (2015). "Nine Tenets on the Nature of Value." 23rd Annual Conference of the International Group for Lean Construction, Perth, Australia, 475485.

Drevland, F., and Svalestuen, F. (2013). "Towards a framework for understanding and describing the product value delivered from construction projects." 21th Ann. Conf. of the Int'l. Group for Lean Construction, Fortaleza, Brazil.

Emison, G. A. (2006). "The complex challenges of ethical choices by engineers in public service." Science and Engineering Ethics, 12(2), 233-244.

Focault, M. (1976). Histoire de la sexualité: la volonté de savoir. Gallimard, Paris.

Habermas, J. (1992). Moral Consciousness and Communicative Action. Polity Press, Cambridge.

Harris, C. E. (2008). "The Good Engineer: Giving Virtue its Due in Engineering Ethics.” Science and Engineering Ethics, 14(2), 153. 
Holbrook, M. B. (1998). Consumer Value : A Framework for Analysis and Research. Routledge, London, GBR.

Jones, T. M. (1991). "Ethical Decision Making by Individuals in Organizations: An IssueContingent Model." The Academy of Management Review, 16(2), 366-395.

Kant, I. (1828). Critik der reinen Vernuft. Leipzig.

Lencioni, P. (2002). The Five Dysfunctions of a Team: A Leadership Fable. Jossey-Bass, San Francisco.

Lévinas, E. (2014). Le temps et l'autre. Collection Quadrige, PUF, Paris.

Mesa, H. A., Molenaar, K. R., and Alarcón, L. F. (2016). "Exploring performance of the integrated project delivery process on complex building projects." International Journal of Project Management, 34(7), 1089-1101.

Mill, J. S. (2002). Utilitarianism. Hackett Publishing Company, Indianapolis/Cambridge.

Perry, M. S. (2014). Moral Dilemmas, Identity, and Our Moral Condition: A Guide for the Ethically Perplexed. Algora Publishing, New York.

Ray, R. S., Hornibrook, J., Skitmore, M., and Zarkada-Fraser, A. (1999). "Ethics in tendering. A survey of Australian opinion and practice." Construction Management and Economics, (17), 139-153.

Rooke, J. A., Sapountzis, S., Koskela, L. J., Codinhoto, R., and Kagioglou, M. (2010). "Lean knowledge management: The problem of value.” 18th Ann. Conf. of the Int'l. Group for Lean Construction, Haifa, Israel, 12-21.

Salvatierra-Garrido, J., and Pasquire, C. (2011a). "The first and last value model: Sustainability as a first value delivery of lean construction practice." 19th Annual Conference of the International Group for Lean Construction 2011, IGLC 2011, 1-10.

Salvatierra-Garrido, J., and Pasquire, C. (2011b). "Value theory in lean construction." Journal of Financial Management of Property and Construction, 16(1), 8-18.

Salvatierra-Garrido, J., Pasquire, C., and Miron, L. (2012). "Exploring value concept through the iglc community: Nineteen years of experience." 20th Ann. Conf. of the Int'l. Group for Lean Construction, San Diego, CA, USA.

Sartre, J.-P. (1976). L'être et le néant - Essai d'ontologie phénoménologique. Gallimard, Paris.

Schwartz, S. H., and Bilsky, W. (1987). "Toward a universal psychological structure of human values." Journal of Personality and Social Psychology, 53(3), 550-562.

Thyssen, M. H., Emmitt, S., Bonke, S., and Kirk-Christoffersen, A. (2010). "Facilitating Client Value Creation in the Conceptual Design Phase of Construction Projects: A Workshop Approach.” Architectural Engineering and Design Management, 6(1), 1830 . 